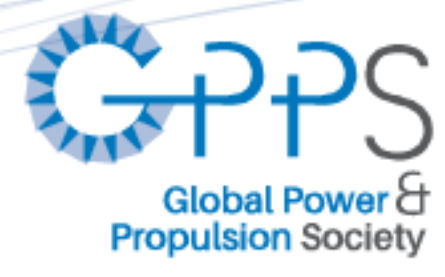

\title{
ATMOSPHERIC CROSSWIND TESTS OF ASPIRATED JET ENGINE INTAKE MODELS
}

\author{
Jan-Hendrik Krone, Lennart Harjes, Philip Frantzheld, Patrick Koch, Daniel Giesecke, Jens Friedrichs \\ Institute of Jet Propulsion and Turbomachinery \\ Technische Universität Braunschweig \\ j-h.krone@ifas.tu-braunschweig.de \\ Braunschweig, Germany
}

\section{ABSTRACT}

The "Technische Universität Braunschweig" has commissioned a Propulsion Test Facility (PTF) for aspirated intake models of jet engines under off-design point conditions. For the commissioning of the unique facility, an aspirated intake test campaign has been carried out. Aim of the campaign was to compare the measured data in the PTF to numerical results and experimental data, which have already been measured in another test facility in the past using the same intake geometry. For the tests the Laminar Flow Reynolds Action (LARA) nacelle has been chosen. The LARA intake has been built and tested in the early 1990s at the "ONERA F1" wind tunnel during the work on hybrid laminar flow technology.

At TU Braunschweig an Aspirated-Intake-Rig (ASI-Rig) with an in-house designed fan stage was worked out, whose fan is located far enough downstream to avoid interaction with the nacelle. For the results, the static pressure distribution at the inner and outer contour of the nacelle lip and the velocity distribution in the fan face during pure crosswind conditions have been compared and analysed. As seen in the results, the PTF pressure distribution at the lip is in good agreement with the numerical and the experimental data from the ONERA. Of particular note is the deviation between the achieved peak Mach number between the two experimental setups, analysed at the $0^{\circ} / 180^{\circ}$ and $90^{\circ}$ section, which can be explained by the Reynolds number effect.

\section{INTRODUCTION}

One of the most challenging design issues within the development of future civil jet engines is the balance of increasing bypass ratios without generating high penalties in cruise drag. Cruise drag is directly coupled to the engine's nacelle diameter which has to increase for higher bypass ratios. Nevertheless, from today's perspective it's the only strategy of meeting future challenges like rising fuel costs and more strict noise emission guidelines. These guidelines are defined in the requirements for future civil aviation, which are called Flightpath 2050 [Kallas and Geoghegan-Quinn (2011)]. Within this program a comprehensive list of actions is formulated including advanced technologies with regards to lowering fuel consumption and decreasing noise emission of jet engines. In order to meet these requirements, jet engine manufacturers are challenged to further improve overall engine efficiency. Over the years, significant improvements of overall engine efficiency were mainly achieved by increasing the propulsive efficiency, which directly depends on the difference between engine exit velocity and flight velocity [Riegler and Bichlmaier (2007)]. The smaller that difference, the higher is the propulsive efficiency, which in turn corresponds to a decreased specific fuel consumption. In general, a lower nozzle exit velocity is related to a lower fan pressure ratio. Keeping the thrust at a constant level, a lower exit velocity has to be compensated by an increased total engine mass flow. This implies a larger fan diameter and thus a higher bypass ratio $\mu$.

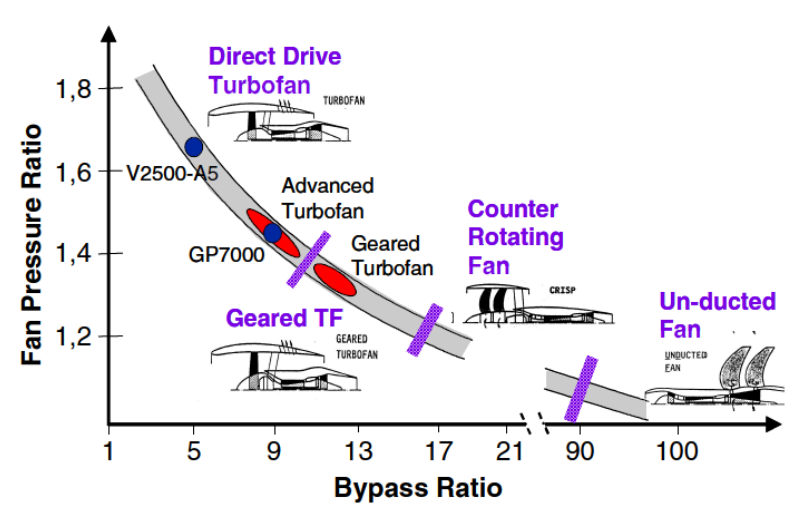

FIGURE 1. Development of Bypass and Fan Pressure Ratio [Riegler and Bichlmaier (2007)] 
That trend is shown in Fig.1. The most widespread technology level today is represented by Direct Drive Turbofans e.g. the V2500-A5 (1992) and the GP7000 (2007). For these engine architectures the fan pressure ratio lies between 1.45 and 1.65 and the maximum achievable bypass ratio is approximately $\mu=9$. Further improvements in propulsive efficiency can only be achieved by new engine concepts. A promising concept is the Geared Turbofan (GTF) [Riegler and Bichlmaier (2007)]. With that concept, bypass ratios up to approximately $\mu=17-18$ are in a conceivable range and fan pressure ratios will further decrease towards values of 1.3 or even lower. Without any counteraction, the fan system becomes more susceptible for aerodynamic instabilities, such as stall and flutter, so that a safe operation is no longer ensured. Accordingly, the interaction of fan performance and intake flow, especially at off-design conditions, is one of the major design criteria for such low pressure fan systems. The opportunity of testing coupled fan-intake systems on scaled models is considered to support the development process and to generate a deeper understanding of the fan-intake interaction.

Classical experimental investigations on nacelle and fan aerodynamics use either wind tunnels or fan rigs. Experiments with a focus on nacelle aerodynamics were e.g. carried out by Quemard et al. (1996). These so-called "Aspirated Intake Tests" determine the isolated intake performances of a representative nacelle model inside a classical wind tunnel. Critical conditions, such as crosswind, are achieved by adjusting the geometric angle of attack within the wind tunnel test section. The engine mass flow itself is generated by using the static pressure difference between the wind tunnel and ambient conditions. By using a secondary air system, a wide flow rate range can be achieved by continuously adjusting the system throttle condition. The rotating fan is not considered within such an experimental setup because of the focus on external and internal nacelle flow. Further low speed investigations were carried out by Probst et al. (2012). For this experimental setup a flow-through nacelle has been investigated in a low speed wind tunnel. Compared to realistic flight conditions for such a "Flow-Through Setup", the mass flow rates through the nacelle are much lower. In order to obtain a representative stall behaviour and pressure distributions the nacelle geometry was adapted [Schulze (2012)].

There exists a wide range of fan rigs for investigations with focus on fan performance. With respect to inlet conditions such compressor test facilities ensure high flow quality as a default configuration. In order to investigate new blade designs or other modifications it is not desired to have an influence triggered by the inlet conditions. Therefore, large settling chambers with turbulence screens and honeycombs ensure both: uniform velocity distributions and low turbulence levels. However, in order to evaluate distorted inlet conditions so-called distortion generators are used. These generators upstream of the rotor are intended to produce a certain local pressure drop or swirl component representing distorted inlet conditions [Wartzek et al. (2016)]. The disadvantage of such methods is, that there is no realistic interaction between the rotor and the distortion generator as it occurs in coupled fan intake systems. For example, the presence of the fan is known to increase the intake's operating range where no separation occurs [Cao et al. (2016)]. Such behaviour can only be investigated by having realistic experimental setups that take all relevant components into account.

The objective of the new propulsion test facility at TU Braunschweig is to provide a combined research setup, including both: wind tunnel capabilities and an operating fan rig. As a result, the fan system can be tested in combination with a representative intake geometry at most critical operation points that occur during a civil flight mission. The advantage of such a setup is to obtain representative intake aerodynamics, fan performances and hence interaction effects that will gain importance for future engine architectures. Since the testing strategy of the propulsion test facility in Braunschweig is an innovative concept, that has never been used before in research on fan-intake investigations, an extensive numerical and experimental validation process is taking place. In this paper the first experimental results on an aspirated-intake test are presented, showing the facility's ability of testing intakes under pure crosswind conditions.

\section{Experimental Setup}

The experimental setup is divided into two parts - the layout of the so-called Propulsion-Test-Facility (PTF) and the design of the Aspirated-Intake-Rig (ASI-Rig) inside the test facility, which generates the flow for aspirated intake models. Basically, the facility layout of the PTF represents an atmospheric wind tunnel (Eiffel-configuration), shown in Fig. 2. The flow is sucked in from the outside via the inlet tower and is redirected via corner vanes. Two screens and a honeycomb improve the flow quality before entering further downstream into the contraction with an area ratio of $A_{\text {in }} / A_{\text {out }}=0.20$. The acceleration of the flow leads to a maximum speed of $M a=0.20$ inside the test section, where the intake model is located. The critical part of the whole facility is the diffuser. Its size is balanced between the maximum possible shaft length of the main drive, which is centred inside the diffuser, and the minimum way for the deceleration of the flow without separation. In order to prevent flow separation the diffuser is divided into three equal sub-diffusers with the same equivalent opening angles and integrated splitters. The diffusor is located between the main blowers and the test section. The blower array is located in the exit area of the diffuser and consists of eight blowers, which have a total power of around $P_{\text {Blower }}=1 \mathrm{MW}$. In the center of the array the electric main drive and the gearbox with a total power of $P_{\text {MainDrive }}=2 \mathrm{MW}$ is located. Downstream of the drive section, turning vanes lead the flow towards the outlet tower [Krone and Friedrichs (2012)].

As a consequence of the long shaft between gearbox and fan rig, the rig itself is not pitchable. In order to generate AoA or pure crosswind conditions, a new distortion concept has been developed. As seen in Fig. 3 the test section is surrounded by a circumferential crosswind duct. At the crosswind outlet the flow is split into two parts. Half of the mass flow is guided above and the other half below the test section. Each stream is accelerated by two blowers. At the crosswind inlet, both streams are merged together and the flow quality is improved via a honeycomb and several screens. Because of the static pressure drop $\Delta p s_{T S}$ in the test section due to the test section velocity, the crosswind duct is designed as a closed loop. Otherwise the pressure gradient be- 


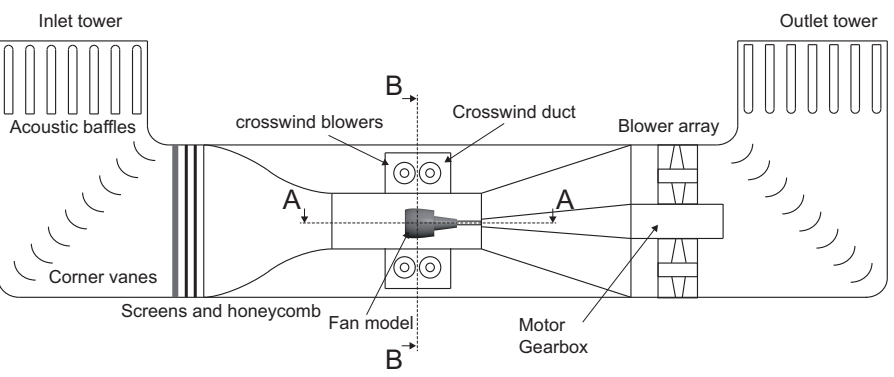

FIGURE 2. Layout of the PTF [Krone and Friedrichs (2014)]

tween the suction and the pressure side of the crosswind blowers would lead to a minimum crosswind speed, that depends on the $\Delta p s_{T S}$ of the test section.

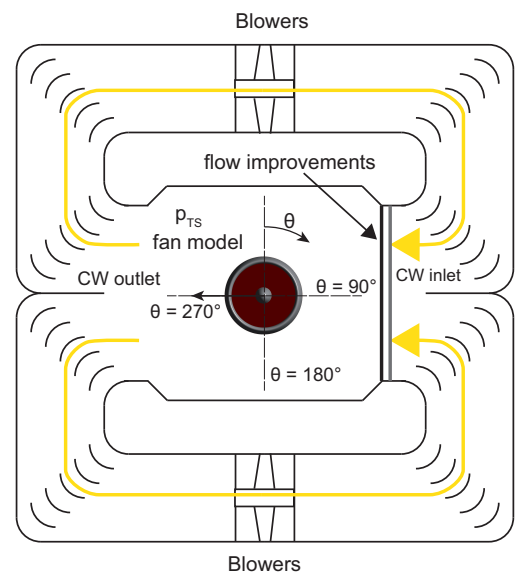

FIGURE 3. Circumferential crosswind duct - section B-B [Krone and Friedrichs (2014)]

To generate an inlet distortion at the test object in the center of the test section, the incoming crosswind leads to a blocking effect, which deflects the main flow, generating the desired AoA (see Fig. 4). As a result, the test section head wind has an AoA $\alpha$ to the fan model's rotation axis during crosswind operation. In order to keep the flow quality of the head wind, the crosswind mass flow itself and the shear layer are not entering the intake model. By changing the ratio between the head- and crosswind speeds, $\alpha$ can be changed steplessly [Krone and Friedrichs (2014)].

In order to validate the PTF and the new crosswind concept, a conventional aspirated nacelle, that has already been examined at a commissioned wind tunnel, is being evaluated and the resulting flow patterns compared.

To implement pure aspirated intake tests, an AspiratedIntake-Rig (ASI-Rig) has been designed and manufactured to generate a flow through the nacelle. As seen in Fig. 5, the power of the main drive shaft is used to drive an aspirating fan. This fan is located further downstream to prevent interaction with the nacelle flow. The ASI-Rig has an axial fan stage with an outer diameter of $D_{c}=0.5 \mathrm{~m}$ and a hub-to-tip ratio of $v=0.6$, see Fig. 5 .

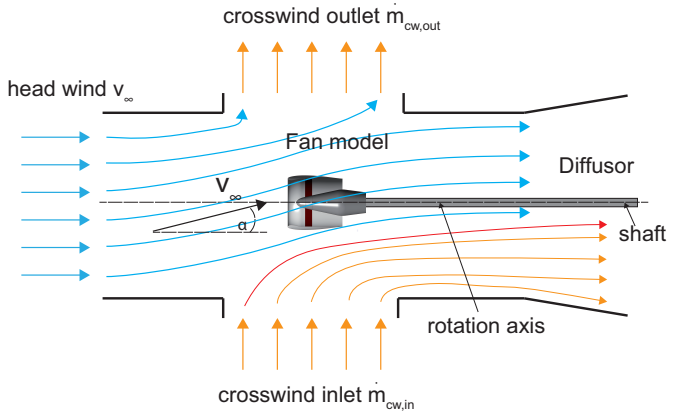

FIGURE 4. Distortion concept - section A-A [Krone and Friedrichs (2014)]

In order to achieve the required Mach number of $M a=0.5$ at nacelle intake, the volume flow rate and pressure rise for the fan stage have been specified. The rotary speed has been set to $n=$ $125 \mathrm{sec}^{-1}$ (7500 rpm) ensuring a sufficient margin to the maximum available speed at the PTF. This finally leads to a mechanical power of $170 \mathrm{~kW}$.

At a fan blade off (FBO) event, the whole structure is able to absorb the maximum shock load of $130 \mathrm{kN}$ without any further damage of the wind tunnel facility. During the run, the rig's status is monitored in real time with several temperature and vibration sensors, that are mounted at each bearing.

TABLE 1. STAGE DESIGN PARAMETERS

\begin{tabular}{lcc}
\hline Design point objectives & Formula & Value \\
\hline Flow coefficient & $\varphi=\frac{4 \dot{V}}{\pi^{2}\left(D_{c}^{2}-D_{h}^{2}\right) D_{c} n}$ & 0.61 \\
Pressure rise coefficient & $\psi_{t s}=\frac{2 \Delta p_{t s}}{\rho\left(\pi D_{c} n\right)^{2}}$ & 0.18 \\
Hub / tip ratio & $v=\frac{D_{h}}{D_{c}}$ & 0.6 \\
Casing diameter & $D_{c}$ & $0.5 \mathrm{~m}$ \\
Tip clearance & $\mathrm{s}$ & $0.5 \mathrm{~mm}$ \\
Rotational speed & $\mathrm{n}$ & $125 \frac{1}{\mathrm{~s}}$ \\
\hline
\end{tabular}

The rotor and stator shown in the meridional view in Fig. 5 comprise 11 respectively 13 blades. The blades are conventional compressor blade sections with NACA 65-series thickness distribution [Members of Staff of Lewis Research Center (1965)] superimposed on circular arc camber lines. The aerodynamic blade section design is similar to those described in Giesecke et al. (2016) excluding blade sweep but using free vortex flow [Horlock (1958)]. Free vortex flow is characterized by incompressible radial equilibrium flow with constant axial velocities through the stage with swirl-free velocities at in- and outlet which is required in the present test rig. As a result of the required flow velocity at nacelle intake, the design parameters listed in Tab. 1 had to be achieved. This includes a flow and total-to-static pressure rise coefficient of $\varphi=0.61$ respectively $\psi_{t s}=0.18$ leading to an 
unfavorable position in the "Smith Chart" (cf. Dickens and Day (2009)) in terms of efficiency. To minimize profile losses, the relationship between the rotor diffusion factor

$$
D F=1-\frac{\cos \beta_{1}^{\prime}}{\cos \beta_{2}^{\prime}}+\frac{\cos \beta_{1}^{\prime}}{2 \sigma_{r o}}\left(\tan \beta_{1}^{\prime}-\tan \beta_{2}^{\prime}\right)
$$

and profile losses

$$
\zeta_{V, r o} \frac{\cos \beta_{2}^{\prime}}{2 \sigma_{r o}} \frac{\cos ^{2} \beta_{2}^{\prime}}{\cos ^{2} \beta_{1}^{\prime}}=f(D F)=0.005+0.16 D F^{4}
$$

with the relative rotor inlet and outlet angle $\beta_{1}^{\prime}$ and $\beta_{2}^{\prime}$ were used while limiting the diffusion factor at $D F<0.6$ at $5 \%$ blade height. For a free vortex design the highest loading is in the range of the aforementioned blade height. With an aspect ratio for the rotor of 1.1 and the stator of 1.25 , its maximum diffusion factors stay below 0.55 and 0.4 near hub. Correspondingly, the flow diffusion, respectively De Haller number, does not drop below 0.7 .

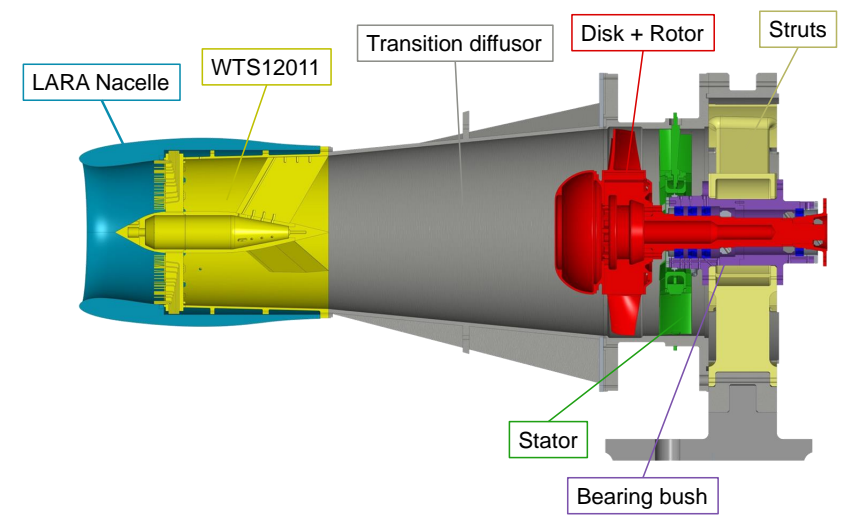

FIGURE 5. Aspirated Intake Rig

For the experiments the LARA nacelle has been chosen, which has been developed in the early 1990s within the work on hybrid laminar flow technology (HLF) by Rolly-Royce, Snecma, Hispano-Suiza, ONERA and the DLR [Lecordix et al. (1996)]. The nacelle has a scale factor of 0.12 and is equipped with six sections of surface static pressure taps on the internal and external lip with 42 probes each. They are located at $\Theta=0^{\circ}, 22.5^{\circ}$, $45^{\circ}, 90^{\circ}, 135^{\circ}$ and $180^{\circ}$. The distortions in the fan face of the LARA nacelle are measured by using the WTS12011 measuring section. Six long and six short rakes are located circumferentially around the hub cone, with in total 138 local static and total pressure probes. To resolve boundary layer effects, the distance of the total pressure probes at the edge region is shortened - compared to the distance of the rest of the total pressure probes in the rake. The ASI-Rig and the measuring section are connected via the transition diffuser. Figure 6 shows the installed rig inside the test section.

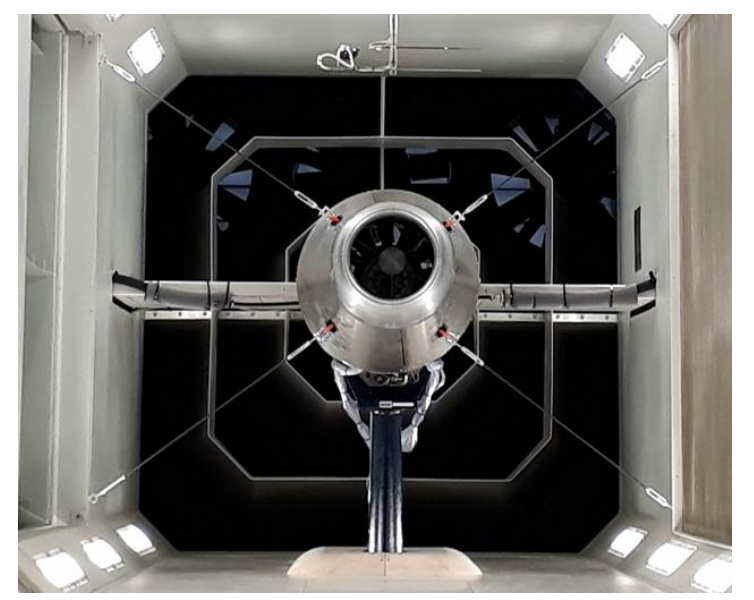

FIGURE 6. Installed LARA Nacelle in the PTF test section

\section{Numerical Setup}

Figure 7 illustrates the simulation domain, which was used to generate numerical data for comparison. With respect to the real experimental setup, a simplified geometry was used in order to decrease the numerical effort in terms of meshing and simulation time. Therefore, the whole rig outer contour as well as the rig support structure (see Fig. 5) is not considered in the model. The simplified setup consists of the test section domain, which includes the LARA-intake. The outer contour of the LARA intake is extended downstream up to the end of the test section domain. The inner part of the intake is extended further downstream (approximately $5 \cdot D_{2}$ ) ensuring numerical robustness at stalled intake conditions.

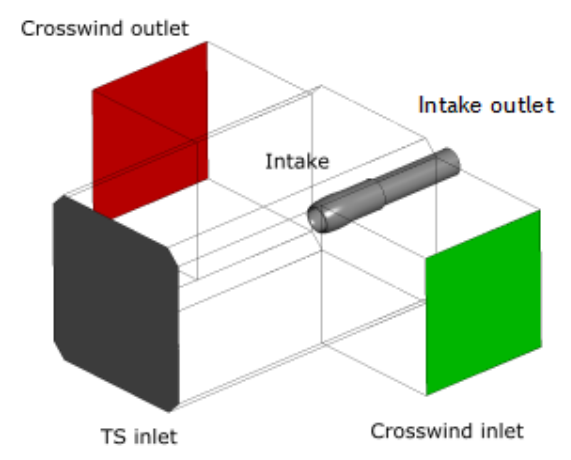

FIGURE 7. Numerical Setup

This method is the standard procedure for stalled intake simulations since interactions of the separation and the intake outlet 
boundary condition is avoided. Crosswind enters the simulation domain through the green crosswind inlet boundary condition, whereas the same amount of mass flow leaves the domain on the opposite site (red plane). Due to the facility crosswind duct architecture, both mass flows have the same value. A velocity inlet is defined at the test section inlet, that includes the ejector effect of the rig. The total mass flow through the test section is higher than the mass flow through the rig, caused by the jet leaving the rig at the rear end of the experimental setup. Continuity is then given by the balance:

$$
\dot{m}_{T S, \text { inlet }}+\dot{m}_{C W, \text { inlet }}=\dot{m}_{T S, \text { outlet }}+\dot{m}_{C W, \text { outlet }}+\dot{m}_{F A N, \text { outlet }}
$$

The mesh on an intake cross section plane is shown in Fig. 8. It is a structured multi block mesh generated by using ICEM CFD. There are no interfaces included, so uncertainties due to interface averaging methods are avoided. The $Y^{+}$-value is about 3 at the outer nacelle-contour and 5 at the area of the spinner. The size of the mesh is adapted from Kellersmann and Friedrichs (2013), where 4 different settings auf mesh densities are analysied for a half modelled LARA nacelle at free field conditions. As a result, the optimum number of nodes is set to around 12.2 million. Adapt to the full modelled LARA nacelle at PTF conditions, this leads to a total number of nodes at around 28.8 million.

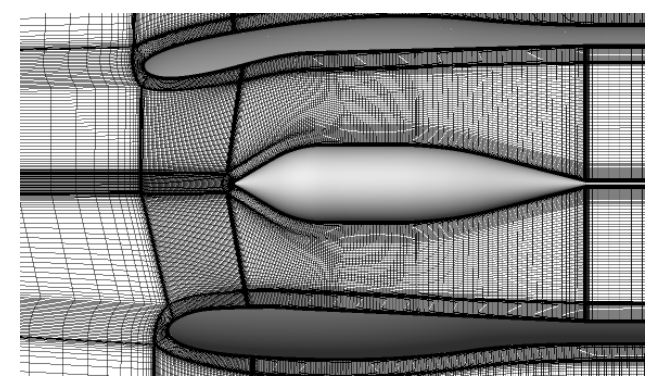

FIGURE 8. Numerical Mesh of the LARA nacelle

Table 2 summarizes the most important boundary conditions. In order to achieve an accurate matching of experimental and numerical results, the boundary conditions were adjusted stepwise during the iterations and the flow velocity was evaluated at a monitoring point located exactly at the position of the master probe inside the test section. In addition to that, the fan face Mach number was monitored and the desired Mach number of 0.45 was matched with an accuracy of $98 \%$ via the intake outlet boundary condition. The simulation was steady state using the standard SST model without any transition models like the $\gamma-R e_{\Theta}$-model, the solver was ANSYS CFX.

\section{RESULTS AND DISCUSSION}

The objective of this test was to validate the crosswind concept of the PTF with an aspirated intake experiment. The LARA nacelle was chosen, because much experimental data is available to compare with. The operating point in this test scenario is a
TABLE 2. SIMULATION BOUNDARY CONDITIONS

\begin{tabular}{lcc}
\hline Boundary & Type & Value \\
\hline TS Inlet & Velocity Inlet & $5 \mathrm{~m} / \mathrm{s}$ \\
CW Inlet & Velocity Inlet & $11.3 \mathrm{~m} / \mathrm{s}$ \\
CW Outlet & Velocity Outlet & $11.3 \mathrm{~m} / \mathrm{s}$ \\
Intake Outlet & Ave. stat. pressure Outlet & $100800 \mathrm{~Pa}$. \\
\hline
\end{tabular}

pure crosswind test case with $v_{C W}=11.3 \mathrm{~ms}^{-1}$ and a fan face Mach number of $M a=0.45$. Two results are discussed in this section - the distortion pattern in the fan face and the nacelle pressure distribution.
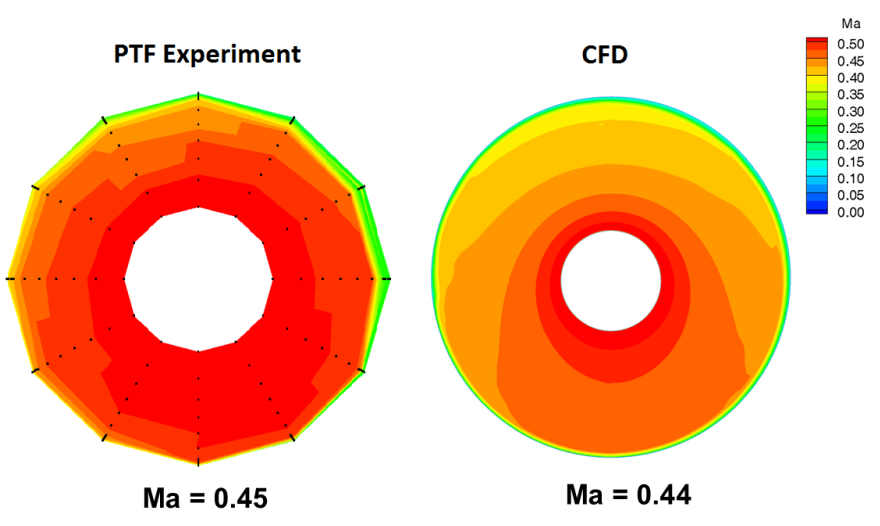

FIGURE 9. Fan face Mach number, left: exp., right: CFD

The distortion pattern in the fan face is shown in Fig. 9 for the experimental and numerical results. They are plotted looking downstream on the fan face with crosswind coming from the right-hand side. All total pressure probes are highlighted as black dots in the experimental results. The area averaged Mach number is calculated in the post process by evaluating all static and total pressure probes as well as the four circumferential temperature probes in the fan face with $R_{S}=287.8 \mathrm{~J} \mathrm{~kg}^{-1} \mathrm{~K}^{-1}, \kappa=1.4$ and $\rho=1.225 \mathrm{~kg} \mathrm{~m}^{-3}$.

$$
q=p_{t, T S}-p_{s, T S} \quad v=\sqrt{\frac{2 \cdot q}{\rho}} \quad M a=\frac{v}{\sqrt{\kappa R_{s} T}}
$$

The inlet distortion for the experimental setup forms a classical "smile pattern". It is slightly shifted towards the top of the nacelle as a result of the thinner upper lip. Compared to the CFD result the Mach number is slightly higher in the experiment. The reason for this is that the exact area averaged Mach number is calculated in the post process by evaluating all measured pressures. Hence it is not possible to determine the exact Mach number during measuring. 
Total pressure loss in the boundary layer can be seen in both plots. The measured one seems to be slightly thicker on the $45^{\circ}$-section. This effect is significant for the experimental result - for the CFD results the impact of the cross wind can only be seen by a tiny bit thicker area of $M a=0.3$. A closer look on the probe position shows, that this effect is probably a result of the measurement resolution and contour plot interpolation between the probes. Additionally the numerical SST model has troubles with the prediction of separated flow. In general the representative result demonstrates that the crosswind concept within the facility is capable of generating representative inlet flow conditions, which can be measured with the existing measurement section WTS12011.

The nacelle pressure distributions for four vicarious sections are evaluated and shown in Fig. 10 to 13, while the sections can be identified in Fig. 14. The experimental data has been compared to the numerical results and the ONERA experiment, which had been carried out with the exact same nacelle.

All pressure distributions are plotted as isentropic Mach

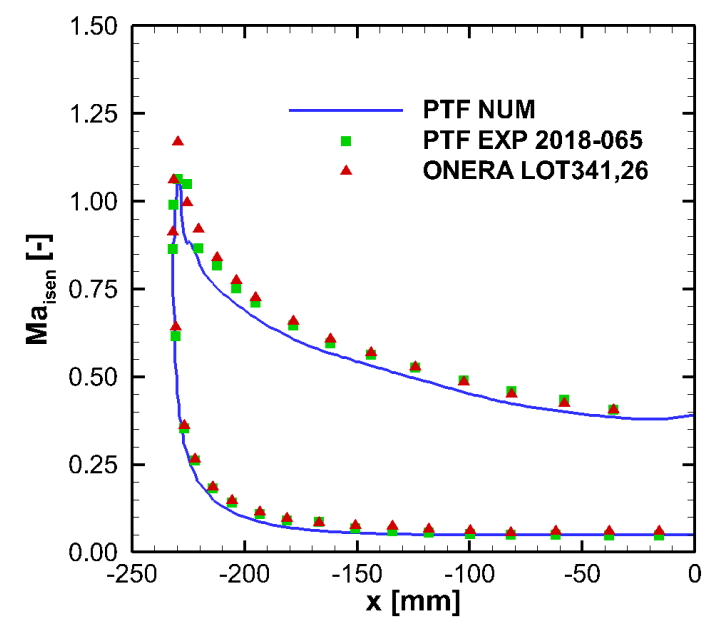

FIGURE 10. Static pressure distribution $0^{\circ}$

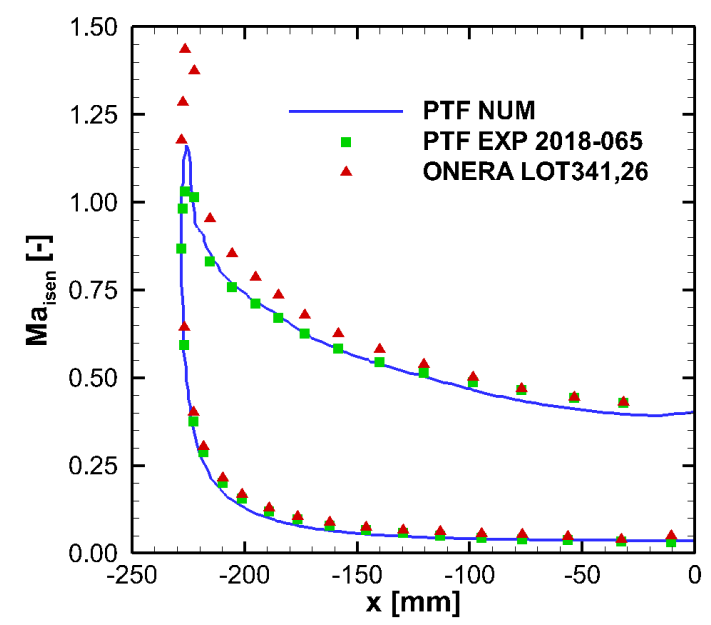

FIGURE 11. Static pressure distribution $45^{\circ}$ numbers, with $\kappa=1.4, p_{s, T S}$ as static nacelle pressure referenced to the test section pressure, $p_{T S, A m b}$ as pressure between the test section and environment and $p_{A m b}$ as the absolute ambient pressure.

$$
\begin{gathered}
M a_{\text {isen }}=\sqrt{\frac{2}{\kappa-1} \cdot\left[\left(\frac{p_{t}}{p}\right)^{\frac{\kappa-1}{\kappa}}-1\right]} \\
\left(\frac{p_{t}}{p}\right)=\frac{p_{T S, A m b}+p_{A m b}}{p_{s, T S}+p_{T S, A m b}+p_{A m b}}
\end{gathered}
$$

Numerical and experimental results of the PTF measurement are in very good agreement. Even the measured peak Mach number hits the calculated one. The numerical setup was build up to represent the PTF experiment. Therefore environmental pressure was set as boundary condition, so that both results contain the same Reynolds number. The accordance between the estimated and measured pressure distribution is very high over the entire

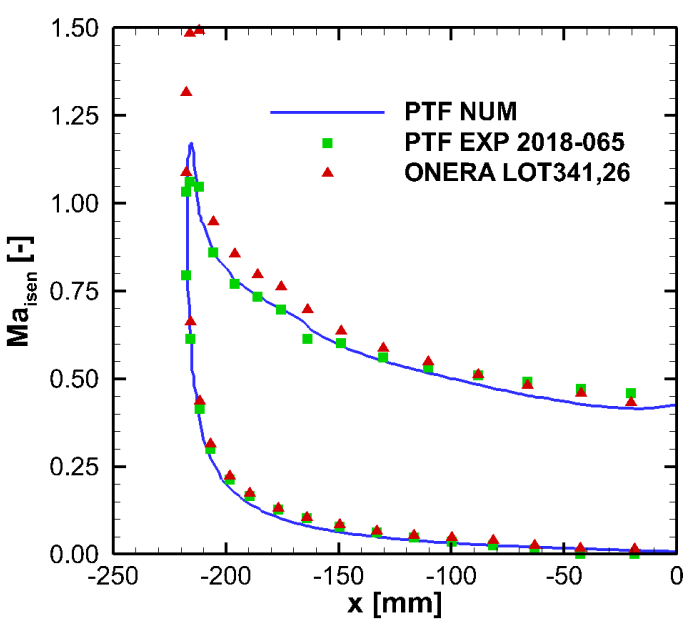

FIGURE 12. Static pressure distribution $90^{\circ}$

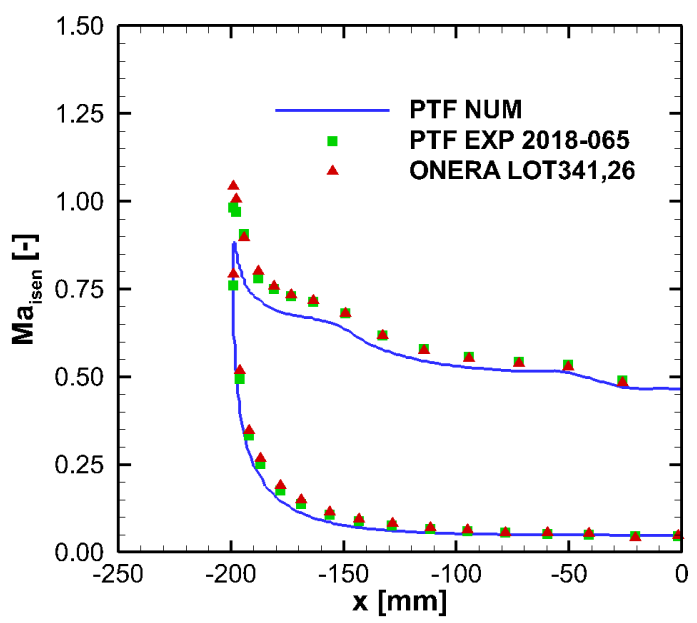

FIGURE 13. Static pressure distribution $180^{\circ}$ 


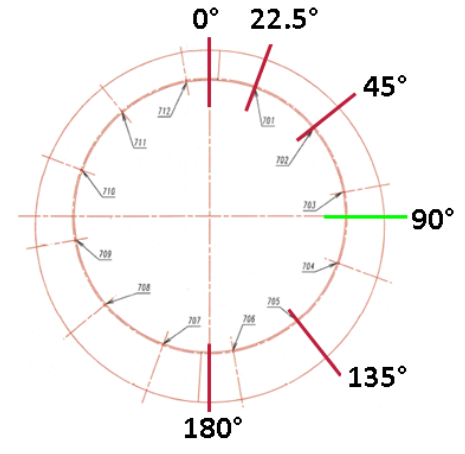

FIGURE 14. Front view of LARA nacelle, Measuring sections

plot.

The ONERA data comes from Lot 341 Point 26 from 20Apr-1994 with $p_{T S}=384336 \mathrm{~Pa}$ and $v_{C W}=11.3 \mathrm{~m} \mathrm{~s}^{-1}$. Compared to the ONERA data the PTF results indicate a high accordance except for the peak Mach number. The Reynolds number, which is 3,8 times lower in the PTF setup than in the pressurised ONERA F1 wind tunnel, has an effect on the pressure distributions and will be discussed in the following.

Experiments with the NACA 4412 profile at different Reynolds numbers and different angles of attack pointed out the following: At low angles of attack the Reynolds number has no effect on the pressure distribution, where at high angles of attack an increase of the Reynolds number leads to higher suction peaks, see Fig. 15 [Pinkerton (1938)].
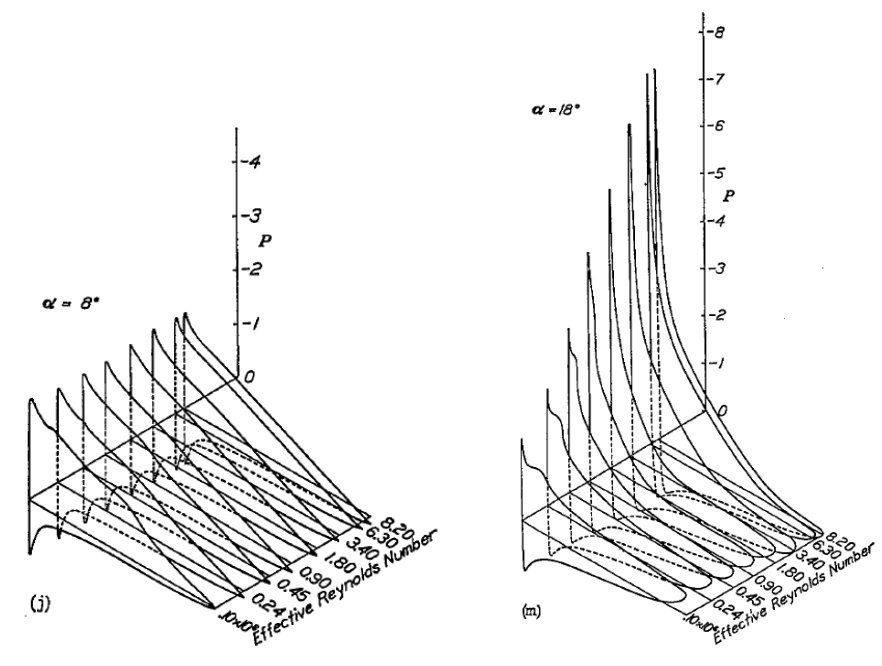

FIGURE 15. Pressure distribution diagram for the NACA 4412 airfoil [Pinkerton (1938)]

Compared to the ONERA data the PTF measured peak Mach number fits very well at the $0^{\circ}$-section, which is at the 12 o'clock position of the nacelle, see Fig. 10. There the crosswind is not increasing the nacelle's angle of attack, so that the pressure distribution is not effected by the Reynolds number, as described in the above mentioned NACA report. At the $45^{\circ}$ - and $90^{\circ}$-section the crosswind increases the angle of attack strongly, see Fig. 11 and 12. Similar to the NACA results this leads to higher peaks at higher Reynolds numbers. At the $180^{\circ}$-section the peak of the PTF and ONERA measurement is nearly the same similar to the $0^{\circ}$-section.

Further studies will evaluate the effect of both, crosswind speed and Reynolds number variation to find the connection between this two parameters.

\section{CONCLUSIONS}

During commissioning of the PTF facility, one of the first test campaigns examines the intake flow conditions at the fan face of an engine nacelle under pure crosswind conditions. The setup consists of an aspirated intake rig, which uses a measurement section for the intake distortion pattern at the axial position of the regular fan-stage. The mass flow through the nacelle is generated by a rotating fan further downstream of the facility. In order to have a comparison with existing parameters, the LARA nacelle, which has already been examined by ONERA, was used with the installed rig. In addition to the ONERA data, the collected test results were compared with numerical calculations of the presented setup. The static pressure distribution of the nacelle has been compared between all three inputs. A comparison of the distortion pattern could only be carried out between the CFD results and the experimental data of the performed tests.

The obtained first results are very promising. The facility is able to reproduce the results of the ONERA facility, which uses a different approach towards crosswind tests on flow through intakes of scaled models, to a good approximation. In the future, this test facility is going to carry out detailed tests regarding different test vehicles and test conditions, using the full potential of the combination of powered intakes in cross- and headwind conditions.

$\begin{array}{ll}\begin{array}{l}\text { NOMENCLATURE } \\ \text { Latin }\end{array} & \\ A_{\text {in }} & \text { Inlet area } \\ A_{\text {out }} & \text { Outlet area } \\ D & \text { Diameter } \\ D F & \text { Diffusion factor } \\ M a & \text { Mach number } \\ n & \text { Rotational speed } \\ p & \text { Pressure } \\ P_{\text {Blower }} & \text { Total power of the main blowers } \\ P_{\text {MainDrive }} & \text { Total power of the main drive } \\ q & \text { Dynamic pressure } \\ R_{S} & \text { Specific gas constant } \\ s & \text { Tip clearance } \\ T & \text { Temperature } \\ v & \text { Velocity } \\ \dot{V} & \text { Volume flow rate }\end{array}$

\section{Greek}

$\alpha \quad$ Angle of attack 
$\beta \quad$ Absolute flow angle

$\beta^{\prime} \quad$ Relative flow angle

$\Delta p s_{T S} \quad$ Static pressure drop of the test section

$v \quad$ Hub-to-tip ratio

$\kappa \quad$ Heat capacity ratio

$\rho \quad$ Density

$\sigma \quad$ Solidity

$\varphi \quad$ Flow coefficient

$\psi \quad$ Pressure rise coefficient

\section{Subscripts}

$\begin{array}{ll}\text { Amb } & \text { Ambient } \\ \text { c } & \text { Casing } \\ \mathrm{CW} & \text { Crosswind } \\ \mathrm{h} & \text { Hub } \\ \text { isen } & \text { Isentropic } \\ \text { ro } & \text { Rotor } \\ \mathrm{s} & \text { Static } \\ \mathrm{t} & \text { Total } \\ \text { ts } & \text { Total-to-static } \\ \mathrm{TS} & \text { Test section } \\ 1 & \text { Rotor inlet station } \\ 2 & \text { Rotor outlet / stator inlet station }\end{array}$

\section{Abbreviations}

$\begin{array}{ll}\text { AoA } & \text { Angel of Attack } \\ \text { FBO } & \text { Fan Blade Off } \\ \text { HLF } & \text { Hybrid Laminar Flow } \\ \text { LARA } & \text { Laminar Flow Research Action } \\ \text { NACA } & \text { National Advisory Committee for Aeronautics } \\ \text { PTF } & \text { Propulsion-Test-Facility } \\ \text { GTF } & \text { Geared Turbo Fan }\end{array}$

\section{ACKNOWLEDGMENTS}

This project has been supported and funded in parts by Rolls-Royce Germany. This support is most gratefully acknowledged.

\section{References}

Cao, T., Rao, V., Tucker, P., R. Smith, A., Slaby, M. and Sheaf, C. (2016). Fan-intake interaction under high incidence, Journal of Engineering for Gas Turbines and Power .

Dickens, T. and Day, I. (2009). The design of highly loaded axial compressors, Proceeings of ASMETurbo Expo 209: Power for Land, Sea and Air, Orlando, Florida, USA (GT2009-59291).

Giesecke, D., Friedrichs, J., Stark, U. and Dierks, M. (2016). Aerodynamic and acoustic performance of a single stage axial fan with extensive blade sweep designed to limit noise emissions, Proceedings of ASME Turbo Expo 2016: Turbomachin- ery Technical Conference and Exposition, Seoul, South Korea (GT2016-56555).

Horlock, J. H. (1958). Axial Flow Compressors: Fluid Mechanics and Thermodynamics, Butterworths Scientific Publications.

Kallas, S. and Geoghegan-Quinn, M. (2011). Flightpath 2050 europe's vision for aviation - report of the high level group on aviation research, Technical report, Publications Office of the European Union.

Kellersmann, A. and Friedrichs, J. (2013). Validierung von anstroemungsuntersuchungen bei triebwerkspropulsoren, Diplomarbeit .

Krone, J.-H. and Friedrichs, J. (2012). Design of a fan-testfacility with axial flow and crosswind capabilities, ISROMAC Paper (ISROMAC-14).

Krone, J.-H. and Friedrichs, J. (2014). Generation of intake distortion due to angle of attack for a high bypass turbofan model, ASME Paper (IMECE2014-38097).

Lecordix, J., Mullender, A., Lecossais, E., Godard, J. and Hepperle, M. (1996). Hybrid laminar flow nacelle design, ICAS Paper (ICAS-96-2.3.4).

Members of Staff of Lewis Research Center (1965). Aerodynamic Design of Axial-Flow Compressors - NASA SP-36, National Aeronautics and Space Administration (NASA).

Pinkerton, R. M. (1938). The variation with reynolds number of pressure distribution over an airfoil section, NACA Technical Report 613.

Probst, A., Schulze, S., Kähler, C. and Radespiel, R. (2012). Reynolds-stress modelling of subsonic and transonic inlet stall compared to measurements.

Quemard, C., Garcon, F. and Raynal, J.-C. (1996). High Reynolds Number Air Intake Tests in the ONERA F1 and S1MA Wind-Tunnels.

Riegler, C. and Bichlmaier, C. (2007). The geared turbofan technology opportunities, challenges and readiness status.

Schulze, S. (2012). Experimentelle Untersuchungen zur Wirbeldynamik am überziehenden Triebwerkseinlauf, Universität der Bundeswehr München.

Wartzek, F., Schiffer, H.-P., Haug, J. P., Niehuis, R., Bitter, M. and Kähler, C. (2016). Investigation of engine distortion interaction, (GT2016-56208).

Weinig, F. (1935). Die Strömung um die Schaufeln von Turbomaschinen, Verlag von Johann Ambrosius, Leipzig. 